If we join the Community we will be the better for having taken every opportunity of making our principles and our practices known, of looking objectively at what others have achieved, of accustoming ourselves to criticism whether well- or illinformed, and of finding how to overcome the misunderstandings that are unavoidable in international exchanges on this scale. If we do not join we still have a duty to ensure that everything of value that emerges from these co-operative studies is examined here in the context of our own traditions. The question, therefore, is not so much for or against involvement, for we are already involved: it is rather through what channels can we most effectively establish communication; and by what means can we turn our involvement to the best advantage, both in the present phase of political uncertainty and if we find ourselves full members.

\section{Medical Bodies}

The only official forum which exists for the discussion of medical practice within the E.E.C. is the Council of its individual Ministers of Health, in which, of course, this country cannot participats at the present time. Our own eventual access to it, whether professionally or nationally, could only be by way of our own Health Ministers, upon whose advocacy we should have to rely in influencing whatever recommendations were made to the Commission, in which all executive powers are vested. This is not a mechanism upon which the profession in existing member countries has been inclined to place much reliance. Because of this, there was formed in 1956 a Permanent Medical Committee of the E.E.C., drawn from representatives of national medical associations, accompanied often by lawyers and economists, and taking the initiative in discussng and in tendering advice on any subject bearing on medical practice. The decisions of this committee carry some weight, and it is by their exertions that acceptable conditions have been agreed for the reciprocal recognition of basic medical qualifications from next January onwards.

Within the sphere of specialist practice a similar need for reciprocal study exists, because of the acceptance throughout
Europe of a system of laying down educational and other criteria for assessing fitness to take full responsibility in a specialty. The need has been met by the creation of the European Union of Specialist Doctors (U.E.M.S.), whose recommendations have been channelled through the Permanent Committee to the Commission. The Executive Council of the U.E.M.S. is derived, like the Permanent Committee, from national medical associations: it draws advice from 21 multinational specialist groups, each representing a single discipline and made up of nominees of the appropriate scientific associations from each of the six countries.

In the last few years several other groups have set themselves up with the object of furthering particular interests; but it is clearly through the two relatively long-established bodies that influence is to be obtained. Each of them sought the participation of a British observer some years ago, and both have continued to show a lively if critical interest in the organization of medicine in this country. There is therefore, through them, a channel of communication and influence which is already in being, and which we can and should develop in advance of any changes in the political situation. This is something which only the profession can do, and which it will do the better the more widespread is the acceptance of the need for it. The Government, in the meantime, should be engaged in contingency planning with the several medical interests involved, and must at least make clear that it will exercise its prerogative in the obtaining of an adequate period of transition for medicine in the event of the Treaty being signed.

Insularity is a not unreasonable attribute in an island people, and has indeed been responsible for the growth of many of the qualities which we now have the opportunity of deploying in a new field. Our success or failure in benefiting from the opportunity may influence not only the National Health Service but also the status of British medicine for some years to come. The challenge we face may reside not so much in the assault on our standards which many have feared as in the demand for an adaptability to rapidly changing circumstances to which we and our institutions are largely unaccustomed. Here, as perhaps in other sectors of our national life, we have nothing really to fear except complacency.

\title{
Future of the Public Health Service
}

\author{
J. J. A. REID,* T.D., M.D., B.SC., M.R.C.P., M.R.C.P.ED., D.P.H.
}

Dissatisfaction with pay is often no more than a symptom of a more basic pathology, and this is in part true of the position in which the public health service now finds itself. There are, in fact, several major problems facing those who work in this field, one of which is the whole question of how medical care in this country should in future be organized. Related to this is the fact that, though public health is nominally the third branch of the National Health Service, and though its practice has wide and increasing relevance to the work of the other two, it is also part of local government, which, in turn, has its own serious problems, the solution of which still lies in the indefinite future. In the meantime, local health authorities display enormous disparity in size and resources, and, though all nominally provide the same range of sociomedical services, some do so to

- County Medical Officer of Health, Principal School Medical Officer, and County Welfare Officer, Buckinghamshire. no more than indifferent standards, and many offer careers which are likely to attract only the dedicated or those who have failed to make the grade in other branches of medicine.

There are three broad groups of public health doctors, the largest of which comprises those engaged predominantly in clinical work. Next, there are the medical staff of local health authorities, whose work is primarily administrative ; while the third group consists of county district medical officers of health, who usually have a mixture of administrative and clinical duties to perform. All three have problems in relation to their present and future functions, their career structures, and their salaries. In addition, considerable attention is currently being paid to the relation between medicine and the social sciences, and this, in turn, has given rise to feelings of insecurity which have been particularly felt by the public health branch of the profession, as well as to the taking of rigid attitudes by both sides. 
There is also the perennial debate about the need for medical administrators, which, in its simplest form, revolves around whether it is better to have a doctor with administrative training and ability or an administrator with a different educational background but with a modicum of medical knowledge. The profession as a whole favours medical administrators, and there would certainly appear to be scope within a health service which costs the country more than a thousand million pounds a year for a group of doctors whose chosen specialty is administration. It is at least gratifying to see that the question of providing an appropriate form of postgraduate training for such doctors is currently under review, though this will be of very limited value unless means of financing it can be devised, together with satisfactory and flexible career structures for medical administrators in all branches of the health service.

\section{Changing Attitudes}

It is singularly unfortunate that the public health service should be faced with these problems at the present moment, when various encouraging developments are under way. The teaching of public health and social medicine to undergraduates is at last being taken more seriously, even within some of the medical schools of the University of London. In the community, historical rivalries are dying, and the provision of individual services is being increasingly looked upon in terms of who can best do any particular job, rather than on a basis of exclusive claims resting on the inflexible perpetuation of patterns of services devised to meet the sociomedical conditions of a bygone age.

The role of the general practitioner as the primary provider of medical care for the entire family is widely accepted, and he is beginning to take over various functions such as antenatal and child health clinics, as well as school health work, traditionally carried out by the public health service in order to fill gaps which formerly existed in medical care. Such work will, in the long term, be carried out by general practitioners whose organization and whose undergraduate and subsequent training have fitted them for their tasks, and they will be assisted by health visitors and by district nurses and midwives seconded to them from the public health service. Schemes of attachment are proliferating throughout the country, and bring with them all the advantages accruing from the pooling of knowledge and of resources which, in turn, leads to increased selectivity of work and greater job satisfaction while at the same time providing a team approach which is appreciated by patients. The movement towards the sharing of premises by family doctors and public health personnel is in keeping with the new outlook, and it is also coming to be accepted that the medical officer of health can supply much of the administrative support which is essential to family doctors in the modern practice of medicine. The realization that prevention and cure are not separate processes, and the growing importance of epidemiology, of the ability to identify special groups in the population, of screening techniques, and of other specialized preventive and aftercare services, all point to the need for close administrative linkage between public health and general practice.

The medical officer of health is similarly fostering bonds between the services under his control and those of the hospital, and once again this process is proving mutually advantageous. Hospital resources are expensive, and for this reason, as well as because it is often more acceptable to patients, domiciliary care is frequently preferable. The joint training and use of staff, the provision of co-ordinated schemes of social work and aftercare, and the evolution of mutually agreed admission and discharge policies are bringing the hospital and public health services more closely together than they have been since before the advent of the National Health Service in 1948, and are helping to link hospitals more adequately with the communities which they serve.
It is no exaggeration to claim that the way in which the medical officer of health deploys his services can have profound effects on the entire organization of medical care within the area. If these effects are to be beneficial it is essential that medical officers of health should be good administrators, capable of assessing problems and of being able to arrive at appropriate priorities. Unlike the clinician, the medical administrator sees the results of his work not in hours or days, but in years or even in decades, and this fact must be borne in mind because the present gradual weakening of the public health service will not produce effects which are immediately apparent, but will certainly have long-term consequences that can only be severely damaging to the entire structure of British health services.

\section{Need for a Policy}

What can be done to help the public health service in its present plight, which, if unrelieved, can lead only to demoralization? The frequently canvassed idea of the total reconstruction of the administrative framework of the National Health Service is certainly not imminent, and, incidentally, is not essential to continued progress (Reid, 1965), in addition to which there is always the danger that waiting for legislative change can all too easily become an excuse for total inactivity. Both the hospital service and general practice have been the object of much scrutiny in recent years, and in the case of the latter a particularly significant event was the publication of the Gillie report (Ministry of Health, 1963), which laid down clear guiding principles for the future development of that branch of medicine.

Some time ago (Reid, 1964) I suggested that a working party should be set up to review the present age and qualification structure, recruitment, training, status, and career prospects of public health doctors, as well as the organization of public health services. Some of these tasks are already under way, and a significant contribution has been made by Warren and Cooper (1966), while Warren's continuing studies will provide further badly needed factual information which has hitherto been unavailable. The need remains, however, for a comprehensive review of the public health service, and it is not necessary to await the outcome of the Royal Commission on Local Government, as, whatever the future structure, there will be a continuing need both for clinical staff and for medical administrators at an appropriate local level. The latter will, presumably, be substantially fewer in number than at present, and the manpower requirements of the public health service will similarly diminish as general practitioners come to provide more comprehensive care for families and when the present archaic pattern of local government is reformed. It is, however, essential that any diminution in the number of public health doctors must not be accompanied by a lowering of standards.

It may be contended that there is no need for an inquiry into the public health service, as this has already been carried out in a piecemeal fashion by other committees. It is true, to give only a few examples, that the Gillie committee made several recommendations concerning aspects of public health work; that the Sheldon committee has been studying child health services; that the Mallaby committee (Brit. med. F., 1967) has recently pronounced on the recruitment and training of medical practitioners in local government; and that the terms of reference of the Seebohm committee impinged on various functions at present carried out by public health staff. It is, however, one thing for the public health service to receive passing attention in the course of reports which deal primarily with other matters, and quite another to establish a committee whose prime duty it would be to inquire into the present state of affairs in that service and to make positive recommendations concerning its future development. Much of the necessary background material for such a study is available, and the com- 
mittee could, if need be, initiate studies where there are gaps in existing knowledge.

Considerable lip-service is paid to the importance of public health, but this will not be sufficient to maintain morale and to boost flagging recruitment in a branch of the profession which, on the evidence of Warren and Cooper's inquiry, is one with an age structure that can only give rise to anxiety. It might be' added that there are also grounds for believing that recruitment has also become unsatisfactory from the qualitative point of view, with the constant danger that a vicious circle could be established whereby indifferent staffing led to a content and a standard of work which were not in keeping with present and future requirements. Unless there is an early and penetrating official inquiry, with wide terms of reference, and unless this is followed by vigorous action, the service will inevitably fail to attract its fair share of the ablest medical graduates. Should this state of affairs come about, the resulting damage would extend far beyond the boundaries of public health, to affect the whole pattern and quality of medical care in this country.

\section{REFERENCES}

Brit. med. F. Suppl., 1967, 2, 10.

Ministry of Health (1963). The Field of Work of the Family Doctor. H M.S.O., London.

Reid, J. J. A.' (1964). Brit. med. f., 2, 1483.

(1965). Publ. Hlth (Lond.), 79, 183.

Warren, M. D., and Cooper, J.'(1966). Med. Offr, 116, 41.

\title{
SELF-HELP IN THE HOSPITALS
}

\section{Oxford Hospital Services Development Trust}

\author{
[From a Special Correspondent]
}

The Oxford Hospital Services Development Trust was established to raise money for improving the quality of service in the hospitals in Oxford. It was registered as a charity in 1965 and it already has $£ 12,000$ a year at its disposal. The Trust is concerned particularly to help those who need quick access to funds for urgent work. Any clinical or research work to be undertaken within the United Oxford Hospitals Group which would improve the quality of treatment or care of patients and which is in urgent need for extra resourceswhether they be equipment, drugs, grants, or even buildingsmay apply to the Trust for funds.

The idea for a voluntarily subscribed trust fund to supplement the State grant to the hospital group came from some of the group's medical staff-in particular Professor W. Ritchie Russell, whose energetic fund-raising had already provided the Oxford Hospitals with considerable extra facilities. In education it is well known that the school with an energetic parents' association can provide its pupils with many extra services. Similarly it is inevitable that hospitals want to develop faster than State funds can allow. This is possible only through other sources of money, of which voluntary contributions, particularly from local people, are a very important part.

The United Oxford Hospitals Group-which consists of two main hospitals (the Churchill and the Radcliffe) and several smaller units-is particularly in need of supplementary financial support. The Group fulfils two roles. Firstly, since the second world war it has been an undergraduate teaching hospital group. Secondly, the Group provides specialist services for the whole Oxford region covering a radius from Oxford of fifty miles. Nevertheless, the group has no large endowment fund like the older London teaching hospitals, most of which have large sums at their disposal. It is only by the most scrupulous budgeting that the Group can keep within its yearly allocation from the State. There is never enough money for all the new projects that research workers and other doctors want to carry out. Hunting for funds from other sources is so time-consuming that a research worker may well have left before his money has been allocated. Hence a permanent trust fund, devoted exclusively to the needs of the hospital group and quickly accessible, seemed the only answer to all of these problems.

\section{Setting up the Trust}

In setting up the Trust Professor Ritchie Russell and his colleagues first asked some of the leading laymen of Oxford to act as trustees. A small board of trustees was formed representing the major interests in the community-including industry, trade unions, the University, and the hospitals them- selves. The medical staff contributed about $£ 300$ to cover the administrative and legal costs of setting up the Trust and to start off the fund. Even before the Trust had been publicly inaugurated many local firms and private individuals had contributed a total of several thousand pounds. The public inauguration and a well-attended press conference ${ }^{1}$ have been the only organized publicity that the Trust has been given so far.

The money raised by the Trust is placed only in short-term investments. Professor Ritchie Russell pointed out that the Trustees needed to be able to get at the money when they needed it, rather than to save it all up. The continued existence of the Trust, therefore, depends on regular contributions from the people of Oxford, not just the usual once-and-for-all donation. Already most of the contributors have opted for subscriptions by deeds of covenant or bankers' orders. A particularly interesting type of contribution, moreover, is the weekly contribution of threepence being made by a high proportion of employees at Pressed Steel Fisher, Limited. Mr. M. A. H. Bellhouse, the Deputy-chairman of the company, is a Trustee, and through him the company has taken a particular interest in the Trust. $\mathrm{He}$ approached the unions with the idea that a small weekly deduction from each employee's pay packet might go towards the Trust. The response was highly favourable, and about half of the company's employees at all income levels have joined. the deduction scheme, despite the fact that they have to contract in to do so. Few employees have complained of having paid already for their hospital service through tax and insurance, and the Trustees hope that other industries and occupations in Oxford will contribute in the same way.

Another development has been that good will towards the Trust has been expressed not only in financial terms. Pressed Steel Fisher, Limited, helped the Department of Neurology at the Churchill Hospital to design and build new processing equipment for electroencephalographic records free of charge.

\section{Grants Already Made}

The Trust has already contributed money to several schemes. The first was a grant of $£ 10,000$ towards the building of a general practitioner maternity unit, the remaining $£ 20,000$ needed being raised elsewhere. The 14-bed unit, which adjoins the conventional maternity wards of the Churchill Hospital, is already in use. It accepts only normal births, and, though it was originally intended for confinements that otherwise would have occurred at home, it now accepts some first confinements as well. The unit is served by the same nursing staff as the 